\title{
(6) OPEN ACCESS \\ High Ki67 expression is an independent good prognostic marker in colorectal cancer
}

\author{
Nathaniel Melling, ${ }_{1}^{1}$ Charlotte Marie Kowitz, ${ }^{2}$ Ronald Simon, ${ }^{2}$ Carsten Bokemeyer, ${ }^{3}$ \\ Luigi Terracciano, ${ }^{4}$ Guido Sauter, ${ }^{2}$ Jakob Robert Izbicki, ${ }^{1}$ Andreas Holger Marx ${ }^{2}$
}

\begin{abstract}
${ }^{1}$ Department of Surgery, University Medical Center Hamburg-Eppendorf, Hamburg, Germany ${ }^{2}$ Institute of Pathology, University Medical Center Hamburg-Eppendorf, Hamburg Germany

${ }^{3}$ Department of Oncology, Hematology, BMT with section Pneumology, Hubertus Wald Cancer Center, University Medical Center HamburgEppendorf, Hamburg, Germany ${ }^{4}$ Institute of Pathology, University Hospital Basel, Basel, Switzerland
\end{abstract}

\section{Correspondence to}

Andreas Holger Marx, Institute of Pathology, University Medical Center HamburgEppendorf, Martinistrasse 52, Hamburg 20246, Germany; a.marx@uke.de

NM and CMK contributed equally.

Received 28 February 2015 Revised 21 July 2015 Accepted 26 July 2015 Published Online First 17 August 2015

CrossMark

To cite: Melling $N$, Kowitz CM, Simon R, et al. J Clin Pathol 2016;69: 209-214.

\section{ABSTRACT}

Aims To correlate Ki67 expression with outcome in colorectal cancer (CRC).

Methods Ki67 labelling index (Ki67LI) was analysed by immunohistochemistry on a tissue microarray containing 1800 CRCs. The results were compared with clinicopathological and molecular parameters.

Results Ki67LI was considered low in $26.3 \%$, moderate in $56.7 \%$ and high in $17.0 \%$ of 1653 interpretable CRCs. High Ki67 expression was associated with low tumour stage $(p<0.0001)$ and nodal status $(p=0.0315)$, but not with tumour grade $(p=0.8639)$, histological tumour type $(p=0.1542)$ or tumour localisation, and was an independent prognosticator of favourable survival $(p=0.0121)$. High Ki67 expression was also significantly associated with high-level nuclear $\beta$-catenin and p53 expression ( $p<0.0001$ and $p=0.0095$, respectively).

Conclusions In summary, our data show that high Ki67 expression in CRCs is associated with good clinical outcome. Ki67, p53 and $\beta$-catenin overexpression seem to be linked to CRC, and indicate a cellular state of high proliferative activity. Finally, our findings strongly argue for a clinical utility of Ki67 immunostaining as an independent prognostic biomarker in CRC.

\section{INTRODUCTION}

Colorectal cancer (CRC) is the fourth most common malignant disease with over one million novel cases and over 500000 deaths each year worldwide. ${ }^{1}$ Although recent advances in the management of the disease have improved outcomes, CRC remains the second leading cause of cancer-related death in Western countries. ${ }^{1}$ In advanced metastatic CRC, surgery alone is not curative, and therefore, adjuvant chemotherapy is needed. Patients with nodal negative disease generally show a favourable clinical course. However, approximately one-third of nodenegative CRCs recurs or shows progressive disease, suggesting failure to detect occult disease. ${ }^{2}$ Because aberrant genetic changes occur early in tumour progression, molecular profiling of specific tumour markers in the primary tumour might predict the tumour's metastatic potential. Thus, patients with a potentially aggressive tumour, although not yet metastasised at the time of surgery, might also benefit from adjuvant therapy.

$\mathrm{Ki} 67$ is a nuclear antigen, which is expressed in proliferating cells from G1 to M-phase of the cell cycle. ${ }^{3}$ Many studies have shown a predictive role of Ki67 in a wide range of human malignancies, including gastrointestinal stromal tumours, gastrointestinal neuroendocrine tumours, and prostate and breast cancer. ${ }^{4-8}$ The quantification of Ki67 expression by immunohistochemistry, which is known as the Ki67 labelling index (Ki67LI: percentage of invasive cancer cell nuclei that are positive for Ki67 immunostaining over total invasive cancer cell nuclei present in a histological sample) has become a routine practice in clinical pathology to estimate the growth fraction of a tumour. ${ }^{9}$ For example, in hormone-positive breast cancer, Ki67 is currently used to predict the efficacy of pure hormone receptor blockade without chemotherapy in the neoadjuvant setting. ${ }^{10}{ }^{11}$ In welldifferentiated neuroendocrine tumours (NETs), Ki67 staining of core biopsies of the primary usually provides a reliable method of proliferation assessment for prognosis of metastatic NETs to the liver. ${ }^{12}$ However, only few studies exist on the prognostic role of Ki67 in CRC, and have partially shown contradictory results. ${ }^{13-16}$

To further elucidate the clinical relevance of Ki67 as a prognostic tumour marker, we performed an immunohistochemical study on a large cohort of patients with CRC using our pre-existing CRC microarray containing 1800 CRC specimens with attached clinical follow-up and extensive molecular data. The results of this study show that high Ki67 expression is an independent predictor of favourable outcome in CRC. Thus, patients with CRC that show low Ki67LI may benefit from adjuvant therapy.

\section{PATIENTS AND TISSUE MICROARRAY CONSTRUCTION}

Two different tissue microarrays (TMAs) with a total of 1800 CRC samples were included in this study. The first TMA was manufactured from resection specimens of 1420 patients with CRC at the Institute of Pathology of the University Hospital of Basel. Patients were operated at the Department of Surgery of the University Hospital of Basel between 1988 and 1996. Raw survival data were obtained from the responsible physicians for all of the 1420 patients. The median follow-up time was 46 months (range 1-152 months). The second TMA included samples from 380 patients with CRC whose tumour resection specimens were examined at the Institute of Pathology of the University Medical Center, Hamburg-Eppendorf. Patients were operated at the Department of Surgery of the University Medical Center, Hamburg-Eppendorf from 1993 to 2006. Also for this TMA, raw survival data were available for all of the 380 patients with a median follow-up period of 36 months (range 1-179 months). None of the patients of both cohorts received neoadjuvant therapy. Postoperative therapy was executed according to the guidelines for the treatment of colorectal 
carcinoma. ${ }^{17}$ For both cohorts, no clinical data were available regarding the state of disease progression, especially, there was no separation of the patient population into groups based on RECIST guidelines of stable or responding disease and progressive disease.

TMA construction was as described by Kononen et al. ${ }^{18}$ In brief, H\&E-stained sections were made from each block to define representative tumour regions. Tissue cylinders with a diameter of $0.6 \mathrm{~mm}$ were then punched from tumour areas of each 'donor' tissue block using a home-made semiautomated precision instrument and brought into empty recipient paraffin blocks. Four-micrometre sections of the resulting TMA blocks were transferred to an adhesive-coated slide system (Instrumedics, Hackensack, New Jersey). Patient information and clinical data such as age, sex, localisation and type of the tumour, pathological tumour-node-metastases stage and carcinoma grade were retrospectively retrieved from clinical and pathological databases (table 1). All tumours were reclassified by

Table 1 Clinical and pathological features of colorectal cancers

\begin{tabular}{|c|c|c|c|c|}
\hline \multirow[b]{2}{*}{ Parameter } & & \multicolumn{2}{|c|}{ Ki67LIt } & \multirow[b]{2}{*}{ p Value } \\
\hline & & Mean & SD & \\
\hline All cancers & 1652 & & & \\
\hline \multicolumn{5}{|l|}{ Age $^{*}$} \\
\hline \multicolumn{5}{|l|}{ Age group } \\
\hline$\leq 49$ & 102 & 17.1 & 1.02 & \\
\hline $50-75$ & 1001 & 15.1 & 0.32 & \\
\hline$\geq 76$ & 549 & 14.9 & 0.44 & 0.1253 \\
\hline \multicolumn{5}{|l|}{ Gender } \\
\hline Female & 822 & 15.3 & 0.36 & \\
\hline Male & 830 & 15.0 & 0.36 & 0.6303 \\
\hline \multicolumn{5}{|c|}{ Tumour stage } \\
\hline pT1 & 70 & 18.6 & 1.22 & \\
\hline pT2 & 261 & 19.9 & 0.63 & \\
\hline рT3 & 1071 & 14.6 & 0.31 & \\
\hline pT4 & 250 & 13.6 & 0.64 & $<0.0001$ \\
\hline \multicolumn{5}{|l|}{ Nodal status } \\
\hline pNO & 857 & 15.8 & 0.35 & \\
\hline pN1 & 448 & 14.5 & 0.48 & \\
\hline $\mathrm{pN} 2$ & 347 & 14.4 & 0.55 & 0.0315 \\
\hline \multicolumn{5}{|l|}{ Grading } \\
\hline G1 & 25 & 15.7 & 2.06 & \\
\hline G2 & 1458 & 15.2 & 0.27 & \\
\hline G3 & 169 & 14.8 & 0.79 & 0.8639 \\
\hline \multicolumn{5}{|c|}{ Tumour localisation } \\
\hline Right & 544 & 14.8 & 0.44 & \\
\hline Left & 1108 & 15.3 & 0.31 & 0.8571 \\
\hline \multicolumn{5}{|c|}{ Histological type } \\
\hline Tubular & 1592 & 15.3 & 0.26 & \\
\hline Mucinous & 57 & 12.8 & 1.36 & \\
\hline Others & 3 & 5.0 & 7.26 & 0.1542 \\
\hline \multicolumn{5}{|l|}{$\beta$-Catenin } \\
\hline Negative & 94 & 8.7 & 0.96 & \\
\hline Weak & 109 & 13.8 & 0.37 & \\
\hline Strong & 632 & 15.2 & 0.89 & $<0.0001$ \\
\hline \multicolumn{5}{|l|}{ p53 } \\
\hline Negative & 509 & 13.5 & 0.42 & \\
\hline Positive & 362 & 15.2 & 0.50 & 0.0095 \\
\hline
\end{tabular}

two pathologists (GS and AHM). Follow-up data were obtained from local cancer register boards or via attending physicians. For statistical analyses, tumour localisations were grouped as follows: right-sided cancer (caecum, ascending colon, transverse colon) and left-sided colon (splenic flexure, descending colon, sigmoid colon and rectum). ${ }^{19}$ The usage of tissues and clinical data was according to the Hamburger Krankenhaus Gesetz ( $\$ 12$ HmbKHG) and approved by our local ethical committee.

\section{Ki67 immunohistochemistry}

Standard indirect immunoperoxidase procedures were used for the detection of Ki67 (abcam, clone SPM171, dilution 1:150). Sections were heated in an autoclave at $121^{\circ} \mathrm{C}$ for $10 \mathrm{~min}$ in citrate puffer $(\mathrm{pH}$ 9.0). Diaminobenzidine was used as a chromogen, and sections were counterstained with Mayer's haematoxylin. Only unequivocal nuclear staining, regardless of its intensity, was counted.

For statistical analyses, the staining results were categorised into three groups (weak, moderate, high) according to the percentage of Ki67-positive tumour cells as follows: low Ki67, 0\%-10\%; moderate Ki67, more than $10 \%$ and up to $25 \%$; high Ki67, 25\% and more. This Ki67 labelling system is also currently being applied in grading breast cancer. ${ }^{20}$ The molecular database attached to this TMA contained results on $\beta$-catenin and p53 expression in 1800 cancers.

\section{Statistics}

Statistical calculations were performed with JMP V.10.0.2 software (2012 SAS Institute, North Carolina, USA). The one-way ANOVA (analysis of variance) statistical test with Ki67LI as a continuous variable was used to search for associations between molecular parameters and tumour phenotype. Survival curves were calculated according to Kaplan-Meier. The log-rank test was applied to detect significant survival differences between groups. Cox proportional hazards regression analysis was performed to test the statistical independence and significance between pathological and clinical variables.

\section{RESUTS \\ Technical issues}

A total of $1653(91.8 \%)$ tumour samples were interpretable in our TMA analysis (table 1). Reasons for non-informative cases (147 spots, 8.2\%) included lack of tissue samples or absence of unequivocal cancer tissue in the TMA spot.

\section{Ki67 expression in CRC}

Ki67LI was considered low in $26.3 \%$, moderate in $56.7 \%$ and high in $17.0 \%$ of 1653 interpretable CRCs. Representative images of Ki67 immunohistochemistry (IHC) are given in figure 1. Using Ki67LI as a continuous variable (ANOVA test), Ki67 expression was associated with low tumour stage $(p<0.0001)$ and nodal status $(\mathrm{p}=0.0315)$, but not with tumour grade $(p=0.8639)$, histological tumour type $(p=0.1542)$ or tumour localisation $(\mathrm{p}=0.8571$, table 1$)$.

\section{Association with $\beta$-catenin and $p 53$ expression}

Strong immunohistochemical p53 and $\beta$-catenin positivity was observed in $41.5 \%$ and $75.8 \%$ of all cases, respectively, and was significantly associated with left-sided tumour localisation $(p=0.0222$ and $p=0.0238$, respectively, data not shown). Ki67 expression was significantly related to nuclear $\beta$-catenin and p53 expression $(\mathrm{p}<0.0001$ and $\mathrm{p}=0.0095$, respectively, table 1 , figure 2). 
Figure 1 Representative images of Ki67 expression in colorectal cancer: (A) Ki67 low, (B) Ki67 moderate and (C) Ki67 high expression, magnification $\times 50$ each.
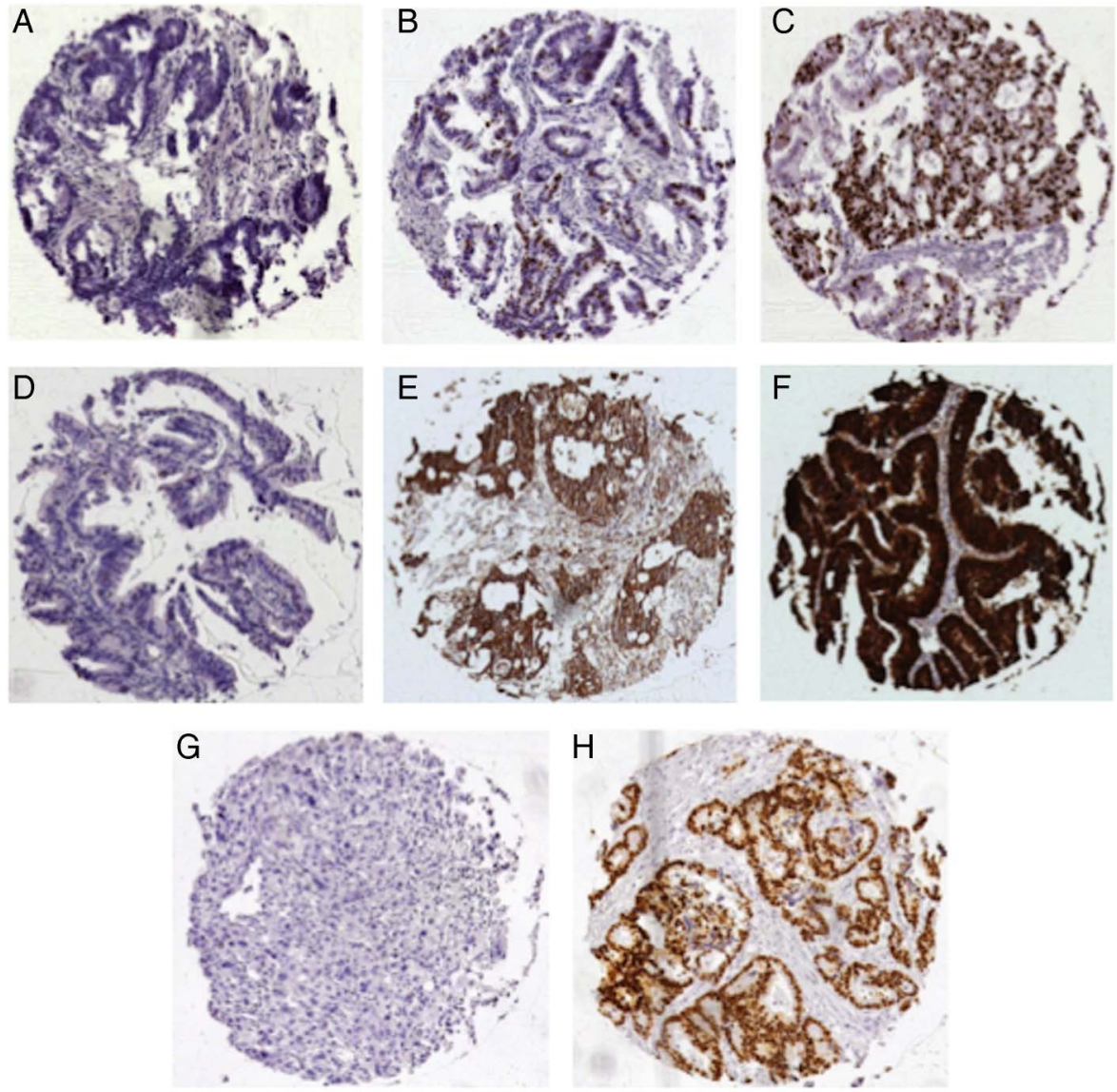

\section{Survival analysis}

As expected, high tumour grade and stage as well as advanced nodal status were associated with poor patient survival (figure 3A-C, $\mathrm{p}<0.0001$ each), while histological tumour type was unrelated to clinical outcome $(p=0.4211)$. Left-sided CRCs (distal to the splenic flexure) were associated with a better

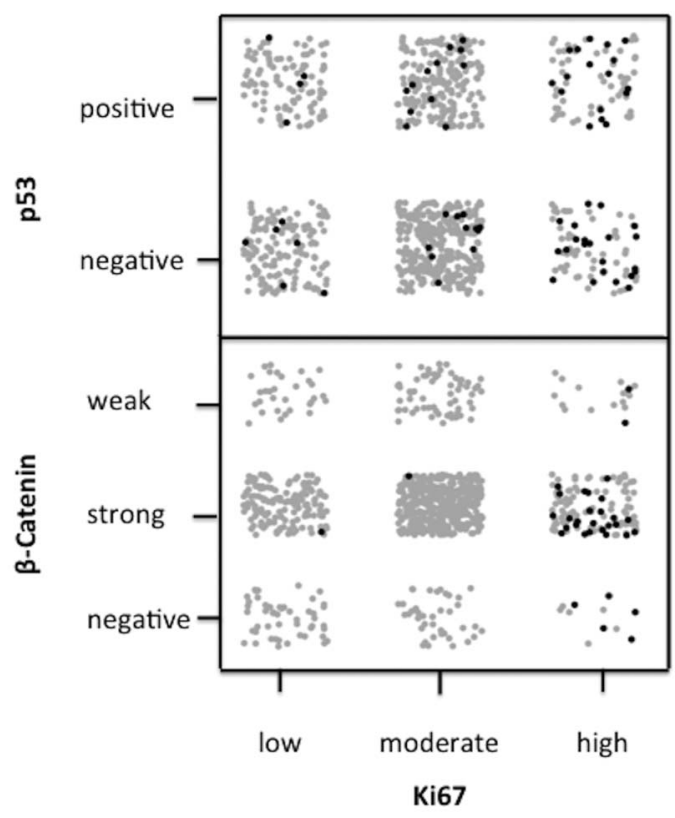

Figure 2 Scatterplot demonstrating correlation graphs of immunostaining of Ki67 with nuclear $\beta$-catenin and p53 expression. prognosis (figure $3 \mathrm{E}, \mathrm{p}=0.0161$ ) as compared with tumours of the right-sided and transverse colon. High Ki67 expression of CRC was significantly related to improved patient survival (Ki67-low vs Ki67-moderate, $p=0.0002$; Ki67-moderate vs Ki67-high, $p=0.0142$; Ki67-low vs Ki67-high, $p<0.0001$; figure 3D). Immunohistochemical p53 and $\beta$-catenin status of the CRC did not show any impact on survival $(p=0.4719$ and $p=0.2799$, respectively). Separate Ki67 analysis of both cohorts alone resulted in similar findings regarding $\mathrm{p}$ values (cohort I: $\mathrm{p}<0.0001$; cohort II: $\mathrm{p}=0.0035$ ). This also held true for the other markers when they were separately tested for each cohort (data not shown).

\section{Multivariable Cox proportional hazards regression model for survival}

In a multivariate analysis (Cox proportional hazards model), including tumour stage, tumour grade, nodal status, tumour localisation, Ki67, p53 and $\beta$-catenin expression, only tumour stage, nodal status and Ki67LI retained significance $(\mathrm{p}<0.0001$, $\mathrm{p}<0.0001$ and 0.0121 , respectively, table 2).

\section{DISCUSSION}

The results of this study show that in CRC, high Ki67 expression is an independent favourable prognostic marker. This finding is comparable with previous results. One earlier study by Salminen et al analysing 146 patients who had CRC with rectal and rectosigmoid cancer had also reported that high proliferative activity measured by $\mathrm{Ki} 67$ is associated with survival improvement compared with patients with low Ki67. ${ }^{14}$ In another study by Reimers et al on 285 patients with stage I-IV colon cancer, Ki67 and cleaved caspase-3 tumour expression 
Figure 3 Association between survival and (A) tumour stage, ${ }^{*} p<0.0001$; (B) nodal status, ${ }^{* *} p<0.0001$; (C) tumour grade, ${ }^{* * *} \mathrm{p}<0.0001$; (D) Ki67 expression (Ki67-low, Ki67-moderate, Ki67-high), ${ }_{\mathrm{p}}<0.0001$ and (E) tumour localisation " $p=0.0280$.
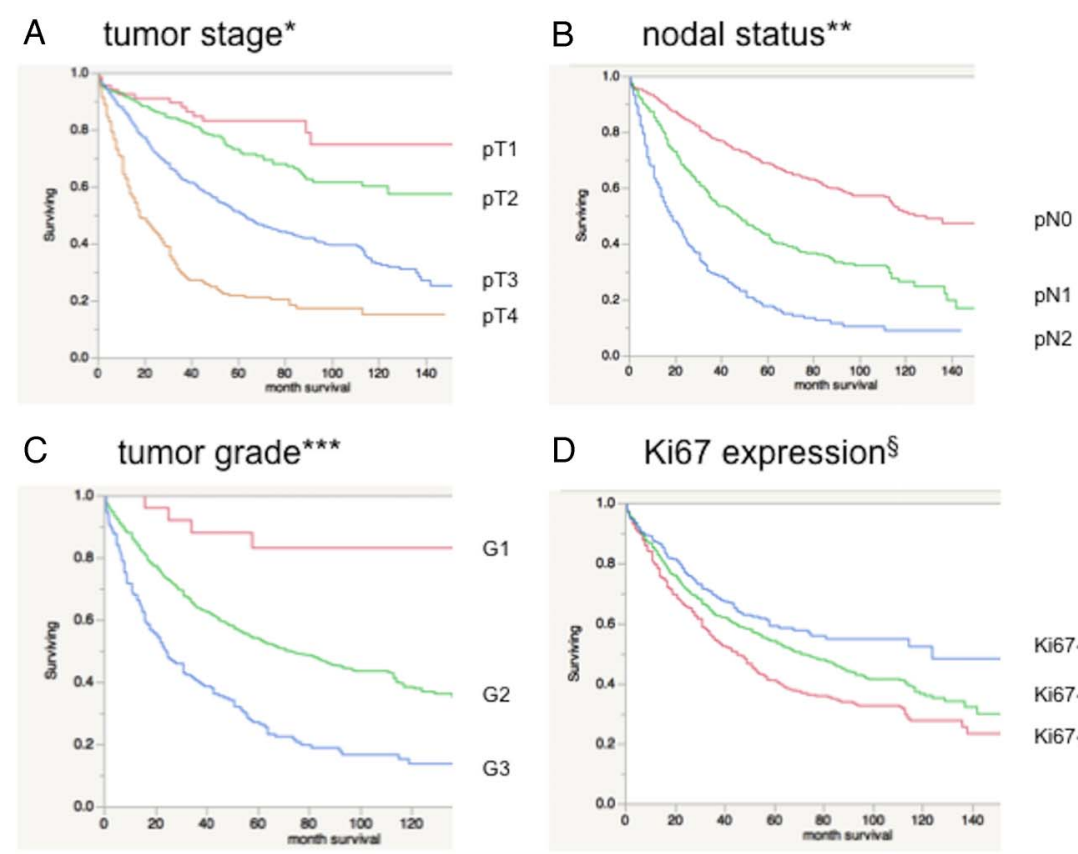

\section{Ki67 expression $\S$}

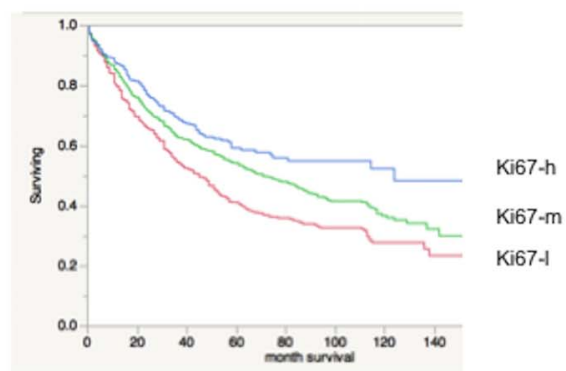

E tumor localization

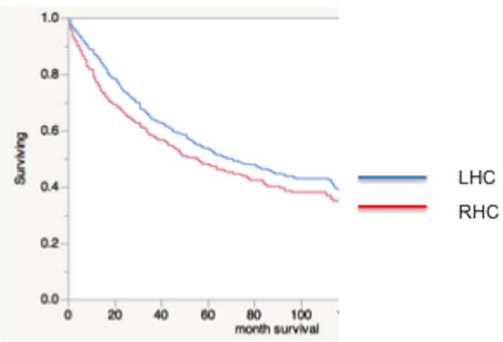

were used to develop the combined apoptosis proliferation parameter and to correlate the results to patient outcome. Interestingly, patients with high levels of both apoptosis and proliferation showed the best outcome perspectives. ${ }^{15}$ Palmqvist et $a l^{16}$ showed that a low Ki67 index at the invasive tumour margin is associated with poor prognosis in Duke's stage B CRC. In contrast, in many other tumour types, including endocrine tumours, gastrointestinal stromal tumour, and head and neck, prostate and breast cancer, high Ki67 index has been linked to poor outcome. ${ }^{4-8} \quad 21-25$ The reason for this discrepancy between the impact of Ki67 expression on prognosis in CRC and a wide range of other human malignancies is unclear. Duchrow et al compared the expression of Ki67 mRNA and protein in $\mathrm{CRC}$, and showed that tumours with a high Ki67

Table 2 Multivariable Cox proportional hazards regression model for survival

\begin{tabular}{|c|c|c|c|c|}
\hline Parameter & Variable & HR & $95 \% \mathrm{Cl}$ & p Value \\
\hline Tumour stage & pT3/4 vs $1 / 2$ & 2.2 & 1.62 to 3.05 & $<0.0001$ \\
\hline Grade & G3/4 vs $1 / 2$ & 1.26 & 0.90 to 1.72 & 0.1807 \\
\hline Nodal status & $\mathrm{N} 1 / 2$ vs N0 & 2.72 & 2.24 to 3.32 & $<0.0001$ \\
\hline $\begin{array}{l}\text { Tumour } \\
\text { localisation }\end{array}$ & $\begin{array}{l}\text { left hemicolon vs right } \\
\text { hemicolon }\end{array}$ & 0.94 & 0.77 to 1.14 & 0.5267 \\
\hline Ki67 IHC & Low/intermediate vs high & 1.41 & 1.08 to 1.90 & 0.0121 \\
\hline p53 IHC & Positive vs negative & 0.89 & 0.74 to 1.07 & 0.2201 \\
\hline$\beta$-Catenin IHC & Weak/strong vs negative & 1.11 & 0.85 to 1.46 & 0.4677 \\
\hline
\end{tabular}

protein level, but low mRNA expression, may proliferate more slowly than expected. They estimated that in a minimum of one-third of CRCs, a significant number of non-cycling tumour cells express Ki67, and in consequence, these tumours might grow more slowly than indicated by the Ki67LI. These Ki67-positive non-cycling tumour cells are probably more stable than tumour cells that cannot achieve cell cycle arrest, and thus, may be more resistant to adjuvant therapies or patient's immune response. $^{26}$ Interestingly, in oestrogen receptor-positive breast cancer, Ki67 expression was suggested to identify a subset of cancers, which may be sensitive to docetaxel treatment in the adjuvant setting. ${ }^{27}$ Comparably, Ki67 determination has also been suggested as a tool in selecting patients with rectal cancer for radiotherapy. ${ }^{13}$ It is well known that the proliferative activity is often heterogeneous within a tumour. ${ }^{12}$ Therefore, it has been recommended that the Ki67LI should be assessed in zones of high proliferation, which are often at the invasive margin of the tumour. ${ }^{11} 16$ However, this can only be accomplished by using whole section slides; on which, the invasive margin of the tumour is clearly identified. In routine clinical practice, core biopsies from the tumour or metastases are usually taken to assess the molecular characteristics of their malignancy. The question remains, whether the Ki67LI obtained from a core needle biopsy adequately represents the whole tumour or metastases. Recently, a study using TMAs of hepatic metastases from well-differentiated NETs demonstrated good correlation between Ki67LI in 1-3 random core biopsies and whole sections of G1 tumours in nearly $100 \%$ and in about $50 \%$ of G2 tumours. Thus, the authors concluded that a single needle core 
biopsy randomly taken from within a tumour or metastasis usually provides adequate proliferation assessment, despite the presence of intratumoral heterogeneity. ${ }^{12}$ Therefore, we assume that Ki67 expression analysis using TMAs constructed from one $0.6 \mathrm{~mm}$ core per patient yields representative results comparable with random core needle biopsies.

The cut-off levels of Ki67 expression used in our study $(\leq 10 \%$ and $\geq 25 \%$ ) are currently being applied in breast cancer diagnostics, and have been shown to be reproducible and significant. However, as suggested for breast cancer, a standardised method of Ki67 assessment is needed for other tumour types, including CRC. ${ }^{11}{ }^{20}$ As expected, Ki67-h was strongly linked to high nuclear $\beta$-catenin and $\mathrm{p} 53$ expression in our cohort (table 1). This observation fits well with the known relationship of $\mathrm{p} 53$, $\beta$-catenin and Ki67 in cell proliferation. ${ }^{28-30} \beta$-Catenin is a key factor of Wingless Int-1 (WNT) signalling, and nuclear translocation of $\beta$-catenin characterises cells with active WNT signalling. ${ }^{31}$ Active WNT signalling leads to enhanced cell proliferation and, thus, to elevated Ki67LI. Mutated p53 accumulates in tumour cells, and thus, serves as a marker of high proliferative activity too (reviewed in Refs 3032 33).

Besides factors that influence cell proliferation, biomarker that plays a critical role in regulating epithelial-mesenchymal transition (EMT) in cancer cells has recently been evaluated for clinical significance. Toiyama $e t a l^{34}$ have shown that increased expression of slug and vimentin, which play a critical role in regulating EMT via downregulation of epithelial markers and upregulation of mesenchymal markers, is significantly associated with poor prognosis. Another study by Satelli et al has suggested that detecting and measuring cell-surface vimentin on the surface of EMT-circulating tumour cells from blood of patients may predict progressive disease in CRC. ${ }^{35}$ However, the relationship between EMT-regulating factors and cell proliferation needs to be further elucidated. Studies on patients with CRC who are divided into groups based on Response Evaluation Criteria in Solid Tumors (RECIST) guidelines in stable or responding disease and progressive disease are needed to define a threshold of Ki67LI that is significantly predicting disease progression.

In summary, our data show that high Ki67 expression in CRCs is associated with good clinical outcome. Ki67, p53 and $\beta$-catenin overexpression seem to be linked to CRC, and indicate a cellular state of high proliferative activity.

Finally, our findings strongly argue for a clinical utility of Ki67 immunostaining as an independent prognostic biomarker in CRC that may contribute to the prognostic evaluation in patients with CRC.

\section{Take home messages}

- High Ki67 expression in colorectal cancers (CRCs) is associated with good clinical outcome.

- Ki67, p53 and $\beta$-catenin overexpression seem to be linked to CRC, and indicate a cellular state of high proliferative activity.

- Ki67 immunostaining may serve as an independent prognostic biomarker in CRC.

Handling editor Cheok Soon Lee

Competing interests None declared.

Ethics approval Local ethical committee.
Provenance and peer review Not commissioned; externally peer reviewed.

Open Access This is an Open Access article distributed in accordance with the Creative Commons Attribution Non Commercial (CC BY-NC 4.0) license, which permits others to distribute, remix, adapt, build upon this work non-commercially, and license their derivative works on different terms, provided the original work is properly cited and the use is non-commercial. See: http://creativecommons.org/ licenses/by-nc/4.0/

\section{REFERENCES}

1 Jemal A, Bray F, Center MM, et al. Global cancer statistics. CA Cancer J Clin 2011;61:69-90.

2 Bilchik AJ, Nora DT, Saha $S$, et al. The use of molecular profiling of early colorectal cancer to predict micrometastases. Arch Surg 2002;137:1377-83.

3 Schwab U, Stein H, Gerdes J, et al. Production of a monoclonal antibody specific for Hodgkin and Sternberg-Reed cells of Hodgkin's disease and a subset of normal lymphoid cells. Nature 1982;299:65-7.

4 de Azambuja E, Cardoso F, de Castro G Jr, et al. Ki-67 as prognostic marker in early breast cancer: a meta-analysis of published studies involving 12,155 patients. Br J Cancer 2007;96:1504-13.

5 Jones RL, Salter J, A'Hern R, et al. The prognostic significance of Ki67 before and after neoadjuvant chemotherapy in breast cancer. Breast Cancer Res Treat 2009;116:53-68.

6 Zhao WY, Xu J, Wang M, et al. Prognostic value of Ki67 index in gastrointestinal stromal tumors. Int J Clin Exp Pathol 2014;7:2298-304.

7 Yamaguchi T, Fujimori T, Tomita S, et al. Clinical validation of the gastrointestinal NET grading system: Ki67 index criteria of the WHO 2010 classification is appropriate to predict metastasis or recurrence. Diagn Pathol 2013;8:65.

8 Pollack A, DeSilvio M, Khor LY, et al. Ki-67 staining is a strong predictor of distant metastasis and mortality for men with prostate cancer treated with radiotherapy plus androgen deprivation: Radiation Therapy Oncology Group Trial 92-02. J Clin Oncol 2004;22:2133-40.

9 Gerdes J, Lemke $\mathrm{H}$, Baisch $\mathrm{H}$, et al. Cell cycle analysis of a cell proliferationassociated human nuclear antigen defined by the monoclonal antibody Ki-67. J Immunol 1984;133:1710-15.

10 Cheang MC, Chia SK, Voduc D, et al. Ki67 index, HER2 status, and prognosis of patients with luminal B breast cancer. J Natl Cancer Inst 2009;101:736-50.

11 Dowsett M, Nielsen TO, A'Hern R, et al. Assessment of Ki67 in breast cancer: recommendations from the International Ki67 in Breast Cancer working group. J Natl Cancer Inst 2011;103:1656-64.

12 Yang Z, Tang LH, Klimstra DS. Effect of tumor heterogeneity on the assessment of Ki67 labeling index in well-differentiated neuroendocrine tumors metastatic to the liver: implications for prognostic stratification. Am J Surg Pathol 2011; 35:853-60.

13 Porschen R, Lohe B, Hengels KJ, et al. Assessment of cell proliferation in colorectal carcinomas using the monoclonal antibody Ki-67. Correlation with pathohistologic criteria and influence of irradiation. Cancer 1989;64:2501-5.

14 Salminen E, Palmu S, Vahlberg T, et al. Increased proliferation activity measured by immunoreactive Ki67 is associated with survival improvement in rectal/recto sigmoid cancer. World J Gastroenterol 2005;11:3245-9.

15 Reimers MS, Zeestraten EC, van Alphen TC, et al. Combined analysis of biomarkers of proliferation and apoptosis in colon cancer: an immunohistochemistry-based study using tissue microarray. Int J Colorectal Dis 2014;29:1043-52.

16 Palmqvist $R$, Sellberg P, Oberg A, et al. Low tumour cell proliferation at the invasive margin is associated with a poor prognosis in Dukes' stage B colorectal cancers. Br J Cancer 1999;79:577-81.

17 Schmiegel W, Pox C, Reinacher-Schick A, et al. S3 guidelines for colorectal carcinoma: results of an evidence-based consensus conference on February 6/7, 2004 and June 8/9, 2007 (for the topics IV, VI and VII). Z Gastroenterol 2010;48:65-136

18 Kononen J, Bubendorf L, Kallioniemi A, et al. Tissue microarrays for highthroughput molecular profiling of tumor specimens. Nat Med 1998; 4:844-7.

19 Bufill JA. Colorectal cancer: evidence for distinct genetic categories based on proximal or distal tumor location. Ann Intern Med 1990;113:779-88.

20 von Wasielewski R, Klopper K, Luck HJ, et al. Improvement of breast cancer grading in punch biopsies: grading with the Ki-67 marker. Pathologe 2006;27:337-45

21 Stuart-Harris R, Caldas C, Pinder SE, et al. Proliferation markers and survival in early breast cancer: a systematic review and meta-analysis of 85 studies in 32,825 patients. Breast 2008;17:323-34.

22 Nishimukai A, Yagi T, Yanai A, et al. High Ki-67 expression and low progesterone receptor expression could independently lead to a worse prognosis for postmenopausal patients with estrogen receptor-positive and HER2-negative breast cancer. Clin Breast Cancer 2015;15:204-11.

23 La Rosa S, Sessa F, Capella C, et al. Prognostic criteria in nonfunctioning pancreatic endocrine tumours. Virchows Arch 1996;429:323-33. 


\section{Original article}

24 Pelosi G, Bresaola E, Bogina G, et al. Endocrine tumors of the pancreas: Ki-67 immunoreactivity on paraffin sections is an independent predictor for malignancy: a comparative study with proliferating-cell nuclear antigen and progesterone receptor protein immunostaining, mitotic index, and other clinicopathologic variables. Hum Pathol 1996;27:1124-34.

25 Szentkuti G, Danos K, Brauswetter D, et al. Correlations between prognosis and regional biomarker profiles in head and neck squamous cell carcinomas. Pathol Oncol Res 2015;21:643-50.

26 Duchrow M, Ziemann T, Windhovel U, et al. Colorectal carcinomas with high MIB-1 labelling indices but low pKi67 mRNA levels correlate with better prognostic outcome. Histopathology 2003;42:566-74.

27 Penault-Llorca F, Andre F, Sagan C, et al. Ki67 expression and docetaxel efficacy in patients with estrogen receptor-positive breast cancer. J Clin Oncol 2009;27:2809-15.

28 Kim NH, Cha YH, Kang SE, et al. p53 regulates nuclear GSK-3 levels through miR-34-mediated Axin2 suppression in colorectal cancer cells. Cell Cycle 2013;12:1578-87.
$29 \mathrm{Kim} N \mathrm{NH}$, Kim HS, Kim NG, et al. p53 and microRNA-34 are suppressors of canonical Wnt signaling. Sci Signal 2011;4:ra71.

30 Clevers H. Wnt/beta-catenin signaling in development and disease. Cell 2006;127:469-80.

31 Morgan RG, Ridsdale J, Tonks A, et al. Factors affecting the nuclear localization of beta-catenin in normal and malignant tissue. J Cell Biochem 2014;115: 1351-61.

32 Jackson JG, Post SM, Lozano G. Regulation of tissue- and stimulus-specific cell fate decisions by p53 in vivo. J Pathol 2011;223:127-36.

33 Goh AM, Coffill CR, Lane DP. The role of mutant p53 in human cancer. J Pathol 2011;223:116-26.

34 Toiyama Y, Yasuda H, Saigusa S, et al. Increased expression of Slug and Vimentin as novel predictive biomarkers for lymph node metastasis and poor prognosis in colorectal cancer. Carcinogenesis 2013;34:2548-57.

35 Satelli A, Mitra A, Brownlee Z, et al. Epithelial-mesenchymal transitioned circulating tumor cells capture for detecting tumor progression. Clin Cancer Res 2015;21:899-906. 